\title{
Significance of Aurora B overexpression in hepatocellular carcinoma. Aurora $B$ Overexpression in HCC
}

\author{
Zhong-Zhe Lin ${ }^{1,2}$, Yung-Ming Jeng ${ }^{3}$, Fu-Chang Hư ${ }^{4}$, Hung-Wei Pan ${ }^{3}$, Hsin-Wei Tsao ${ }^{2}$, Po-Lin Lai ${ }^{3}$, Po-Huang Lee ${ }^{5}$, \\ Ann-Lii Cheng ${ }^{2,6,78^{*}}$, Hey-Chi Hsu ${ }^{3 *}$
}

\begin{abstract}
Background: To investigate the significance of Aurora B expression in hepatocellular carcinoma (HCC).

Methods: The Aurora B and Aurora A mRNA level was measured in 160 HCCs and the paired nontumorous liver tissues by reverse transcription-polymerase chain reaction. Mutations of the $p 53$ and $\beta$-catenin genes were analyzed in 134 and 150 tumors, respectively, by direct sequencing of exon 2 to exon 11 of $p 53$ and exon 3 of $\beta$-catenin. Anticancer effects of AZD1152-HQPA, an Aurora B kinase selective inhibitor, were examined in Huh-7 and Hep3B cell lines.

Results: Aurora B was overexpressed in 98 (61\%) of 160 HCCs and in all 7 HCC cell lines examined. The overexpression of Aurora $B$ was associated with Aurora $A$ overexpression $(P=0.0003)$ and p53 mutation $(P=0.002)$ and was inversely associated with $\beta$-catenin mutation $(P=0.002)$. Aurora $B$ overexpression correlated with worse clinicopathologic characteristics. Multivariate analysis confirmed that Aurora B overexpression was an independent poor prognostic factor, despite its interaction with Aurora A overexpression and mutations of $p 53$ and $\beta$-catenin. In Huh-7 and Hep3B cells, AZD1152-HQPA induced proliferation blockade, histone H3 (Ser10) dephosphorylation, cell cycle disturbance, and apoptosis.
\end{abstract}

Conclusion: Aurora B overexpression is an independent molecular marker predicting tumor invasiveness and poor prognosis of HCC. Aurora B kinase selective inhibitors are potential therapeutic agents for HCC treatment.

\section{Backgroud}

Hepatocellular carcinoma ( $\mathrm{HCC})$ is the leading cause of cancer mortality in Taiwan [1] and many other countries in Asia and Africa [2]. The incidence of HCC is increasing in Europe and the United States [3]. In 2002, HCC became the sixth most common cancer worldwide with 626,000 annual new cases [4]. Despite surgical resection, which provides an opportunity for cure, the majority of patients with HCC have a dismal prognosis [5] because tumor recurrence frequently develops and usually leads to patient's mortality [6]. The development of HCC is closely related to chronic hepatitis B or C,

\footnotetext{
* Correspondence: alcheng@ntu.edu.tw; heychi@ntu.edu.tw

${ }^{2}$ National Center of Excellence for Clinical Trial and Research, National

Taiwan University Hospital, No. 7, Chung-Shan S. Rd., Taipei, 10016, Taiwan

${ }^{3}$ Department of Pathology, National Taiwan University Hospital, No. 7,

Chung-Shan S. Rd., Taipei, 10016, Taiwan

Full list of author information is available at the end of the article
}

cirrhosis of any etiology, and aflatoxin B1 exposure [2]. However, the detailed molecular mechanisms of hepatocarcinogenesis are still not fully understood [7]; molecular factors capable of predicting clinical outcome of HCC and acting as potential therapeutic targets remain limited. The identification of molecular markers related to hepatocarcinogenesis, tumor progression, and poor clinical outcome would benefit patients, providing for better management planning and serving as potential therapeutic targets for novel HCC drug treatments.

Genomic instability has been correlated with hepatocarcinogenesis [8], and increased chromosomal instability has been associated with differentiation status of human HCC [9]. Aurora kinases, a subfamily of serine/ threonine mitotic kinases, are thought to be key molecules required for maintaining accurate cell cycling and genomic stability [10]. We previously showed that 
Aurora $A$ was overexpressed in 137 (61\%) of 224 human HCCs and that the overexpression of Aurora $A$ was associated with aggressive tumor characteristics and poor prognosis of patients [11]. Furthermore, we demonstrated that VE-465, a novel pan-Aurora kinase inhibitor, had anticancer effects in preclinical models of human HCC [12]. These findings indicated that Aurora kinases may be important biomarkers and potential therapeutic targets in $\mathrm{HCC}$.

There are three highly related Aurora kinases in mammals, Aurora A, B, and C. Aurora A and Aurora B share a high degree of sequence homology in their catalytic domains, and overexpression of each has been identified in many human cancers [13].

Despite their sequence similarity, Aurora A and Aurora B differ in chromosomal gene loci, subcellular localization, cellular functions, and signaling substrates [13]. The Aurora A kinase gene is localized to chromosome 20q13.2, and that for Aurora B kinase is localized to chromosome 17p13.1. Aurora A kinase protein is localized in the centrosome and spindle poles and plays important roles in centrosome maturation and spindle assembly [14]. Aurora B kinase, which is a chromosome passenger protein localized in the centromeres during early mitosis and then at the spindle midzone after anaphase, is essential for chromosome biorientation, function of the spindle assembly checkpoint, and cytokinesis [15]. The enthusiasm of exploring Aurora kinases as anticancer therapeutic targets initially centered on Aurora $\mathrm{A}$, but recent studies have demonstrated that several Aurora kinase inhibitors exhibit anticancer activity resembling that of Aurora B disruption induced by genetic methods [16]. Therefore, determination of the distinctive roles in carcinogenesis and individual clinical significance of Aurora A and Aurora B is mandatory. The aims of this study were to elucidate the clinicopathologic significance of Aurora $B$ expression and Aurora $A$ expression in $\mathrm{HCC}$ and to correlate their expression with $p 53$ and $\beta$-catenin mutations, the two most frequently mutated genes in $\mathrm{HCC}[7,11]$.

\section{Methods}

Tissue samples

During the period January 1987 through December 1997, 160 surgically resected, primary unifocal HCCs were selected for this study. After resection, tumor tissues were immediately cut into small pieces, snap frozen in liquid nitrogen, and stored in deep freezer. Patients had received comprehensive pathologic assessment and regular follow-up at National Taiwan University Hospital, as described previously $[17,18]$. This study was compliant with the regulations of the Ethics Committee of the host institution. The 160 patients included 122 men and 38 women with a mean age of 57 years (range,
14-88 years). Serum hepatitis B surface antigen (HBsAg) was detected in 107 cases (67\%) and antihepatitis C virus antibody in 53 (35\%), including 13 positive for both. Elevated $\alpha$-fetoprotein (AFP; $\geq 200 \mathrm{ng} / \mathrm{mL}$ ) was detected in 80 cases (50\%). Liver cirrhosis was found in 61 patients $(38 \%)$. All patients had adequate liver function reserve at the time of surgery. None of the patients had received local or systemic therapy before surgery.

\section{Histological study and tumor staging}

Tumor grade was divided into 3 groups: well-differentiated (grade I, 31 cases), moderately differentiated (grade II, 74 cases), and poorly differentiated (grade IIIIV, 55 cases). The unifocal HCC was staged as stages I, II, IIIA, IIIB, and IV, as described previously $[11,19,20]$. Staging was based on the International Union Against Cancer criteria, with slight modification because HCC tends to spread in the liver via vascular invasion, which is an important unfavorable prognostic factor for this disease [21]. Stage I HCC included tumors that were $\leq$ $2 \mathrm{~cm}$ and showed no evidence of liver and vascular invasion (4 cases). Stage II HCCs included tumors that were $\leq 2 \mathrm{~cm}$ for which vascular invasion was limited to small vessels in the tumor capsule, as well as encapsulated tumors $>2 \mathrm{~cm}$ with no evidence of liver or vascular invasion (62 cases). Stage IIIA HCCs included invasive tumors $>2 \mathrm{~cm}$ with invasion of small vessels in the tumor capsule and/or satellites near the tumor, but no portal vein invasion (25 cases). Stage IIIB HCCs included tumors with invasion of the portal vein branch near the tumor, but not of the distant portal vein in the liver parenchyma (23 cases). Stage IV included tumors with involvement of major portal vein branches, satellites extending deeply into the surrounding liver, tumor rupture, or invasion of the surrounding organs (46 cases). No evidence of regional lymph node or distant metastasis was noted at the time of surgery in any of the cases. Among the 160 patients studied, 149 were eligible for the evaluation of early tumor recurrence (ETR; $\leq 12$ months). Eleven patients who died within 1 year after surgery without objective evidence of tumor recurrence were excluded from the evaluation of ETR.

\section{Reverse transcription-polymerase chain reaction}

Reverse transcription-polymerase chain reaction (RTPCR) was used to determine the mRNA levels of Aurora $A$ and Aurora $B$ in paired HCCs and nontumorous liver samples, as described elsewhere [11,22]. The ribosomal protein $S 26$ mRNA, a housekeeping gene, was used as an internal control [23]. Briefly, total RNA was isolated from the frozen tissues using a guanidium isothiocyanate/CsCl method. RNA was quantified by spectrophotometry at $260 \mathrm{~nm}$. Stock RNA samples were kept in alcohol in deep freezer until used. Complementary DNA 
(cDNA) was prepared from the total RNA of paired HCCs and nontumorous liver samples. Two microliter reverse transcription product, 1.25 units Pro Taq polymerase (Protech Technology Enterprise, Taipei, Taiwan), Pro Taq buffer, and $200 \mu \mathrm{M}$ dATP, dCTP, dGTP, and dTTP (each) were mixed with primer pairs for Aurora $A$, Aurora B, and $S 26$ in a total volume of $30 \mu \mathrm{l}$. Onetube PCR reaction was stopped at the exponential phase of gene amplification: 29 cycles for Aurora A, 32 for Aurora $B$, and 23 for $S 26$. The reaction was performed in an automatic DNA thermal cycler (model 480; Perkin-Elmer Co., Wellesley, MA), with limited reaction reagents (Tag enzyme and dNTPs), and processed with initial heating at $94^{\circ} \mathrm{C}$ for 2 minutes, followed by 29 (Aurora A) or 32 (Aurora B) PCR reaction cycles of $94^{\circ}$ $\mathrm{C}$ for 30 seconds, annealing at $60^{\circ} \mathrm{C}$ for 1 minute, extension at $72^{\circ} \mathrm{C}$ for 1 minute, and a final $72^{\circ} \mathrm{C}$ extension for 10 minutes. The PCR reaction was stopped at cycle 7 (Aurora A) or 10 (Aurora B), and the reaction tubes were quenched on ice to allow adding $S 26$ primers, then complete the final 23 PCR reaction cycles. Primers for amplified genes were as follows: Aurora A-F (AATTG CAGATTTTGgGTGGT), Aurora A-R (AAACTTCAG TAGCATGTTCCTGTC), Aurora $B$-F (ATCGTGG CGCTCAAGGTCCT), Aurora B-R (GATGCACTCT CAAAGGGTGGG), S26-F (CCGTGCCTCCAAGATGACAAAG), S26-R (GTTCGGTCCTTGCGGGCTTC AC). The PCR products were electrophoresed on a $2 \%$ agarose gel. Concentrations of the PCR fragments were determined with the IS-1000 digital imaging system (Alpha Innotech, San Leandro, CA). The Aurora $A$ and Aurora $B$ mRNA levels were determined according to the ratio of signal intensity for Aurora $A$ or $B$ to that of $S 26$ as measured by $1 \mathrm{D}$ Image Analysis software (Kodak Digital Science, Rochester, NY) and scored as high (ratio $>1.0$ ), moderate (ratio $>0.5$ and $\leq 1.0$ ), or low (ratio $\leq 0.5$ ). The Aurora A and Aurora B mRNA levels of nontumorous liver rarely exceeded a ratio of 0.5 , and a ratio $>0.5$ was regarded as overexpression.

\section{Analysis of $p 53$ and $\beta$-catenin mutations}

Mutations of the $p 53$ and $\beta$-catenin genes were analyzed in 134 and 150 tumors, respectively, by direct sequencing of exon 2 to exon 11 of $p 53$ and exon 3 of $\beta$-catenin, as described previously $[17,24,25]$. Samples with incomplete study results were excluded from statistical analysis.

\section{Follow-up observation and assessment of early tumor recurrence}

Early tumor recurrence (ETR) was designated as intrahepatic tumor recurrence or distant metastasis detected by imaging tools, pathology and/or high AFP levels within 12 months. All 160 patients had been followed for more than 5 years or until death. At the end of the follow-up in November 2008, 37 patients remained alive. One hundred forty-nine cases (93\%) were eligible for evaluation of ETR.

Seventy-three (46\%) cases had ETR. Among the 73 patients, $11(15 \%), 26(36 \%), 7$ (10\%), 1 (1\%) received tumor resection, transhepatic arterial embolization, chemotherapy, or radiotherapy, respectively. Fifty-one (32\%) of the 160 cases had late tumor recurrence more than 12 months after the initial hepatectomy. Among the 51 patients, 18 (35\%), 24 (47\%), 4 (8\%), 2 (4\%) received tumor resection, transhepatic arterial embolization, chemotherapy, or radiotherapy, respectively.

\section{Cell culture and reagents}

The liver cancer cell lines Huh-7, HepG2, Hep3B, PLC5, HCC36, HA59T, SK-hep-1, and Tong were cultured in Dulbecco's modified Eagle's medium (DMEM) plus 10\% fetal bovine serum (FBS), supplemented with penicillin and streptomycin. Cells were maintained in a humidified incubator with $5 \% \mathrm{CO}_{2}$ in air at $37^{\circ} \mathrm{C}$.

AZD1152-HQPA is a selective inhibitor of Aurora B (inhibition constant Ki, $0.36 \mathrm{nM}$ ) compared with Aurora A (inhibition constant Ki, $1369 \mathrm{nM}$ ) [26]. AZD1152HQPA, provided by AstraZeneca Pharmaceuticals (Macclesfield, UK), was used for in vitro cell line studies.

\section{Western blot analysis}

Western blotting was performed as described previously [11]. The following primary antibodies were used: antiAurora B (Novus Biologicals, Littleton, CO, USA), antiAurora A (Novus Biologicals), anti- $\alpha$-tubulin antibody (Sigma-Aldrich, St. Louis, MO, USA), anti-phosphorylated histone H3 (Ser10) (Santa Cruz Biotechnology, Inc., Santa Cruz, CA, USA), and anti-phosphorylated Aurora A (T288) (Cell Signaling Technology, Inc., Danvers, MA, USA). The final images were developed with a chemiluminescence reagent.

\section{Cell viability and flow cytometry}

A total of $5 \times 10^{4}$ Huh-7 or Hep3B cells were plated in six-well plates. After overnight culture, cells were treated with DMSO or $1,5,25$, and $125 \mathrm{nM}$ of AZD1152HQPA. At 72 hours of drug treatment, cells were trypsinized and the total number of cells were counted using hemocytometer. Trypan blue dye exclusion assay was used to determine the number of viable cells. The experiments were carried out in 3-4 replicates and repeated trice.

Cells in logarithmical growth were incubated with either AZD1152-HQPA or DMSO for 24 to 48 hours. Cells were labeled with $0.5 \sim 1 \mathrm{~mL}$ propidium iodide $(50$ $\mu \mathrm{g} / \mathrm{mL}$ ) after being trypsinized and fixed in $70 \%$ methanol overnight. Cell cycle profiles and sub-G1 fractions 
were determined using a FACS caliber (Becton Dickinson, San Jose, CA, USA).

\section{Statistical analysis}

Data analyses were carried out with Statistical Analysis System software (version 9.1; SAS Institute, Inc., Cary, NC). Two-tailed $P<0.05$ was considered statistically significant. The $\chi^{2}$, Fisher's exact test, and log-rank test were used for univariate analyses. Multivariate analyses were conducted for ETR, tumor size, stage, and grade by fitting multiple logistic regression models [27]. Time to death was analyzed by fitting multiple Cox's proportional hazards models [28]. In our regression analyses, basic model-fitting techniques for $(a)$ variable selection, (b) goodness-of-fit assessment, and (c) regression diagnostics (including residual analysis, influence analysis, and check of multicollinearity) were used to ensure the quality of the analysis results $[27,28]$.

For the in vitro studies, the mean differences among groups were tested by one-way analysis of variance (ANOVA) followed by multiple comparisons using the Dunnett's post hoc test or the Bonferroni's correction of alpha level.

\section{Results}

\section{Expression of Aurora B mRNA and protein in liver and} hepatocellular carcinoma

Using RT-PCR in the linear range, Aurora $B$ mRNA overexpression was detected in 98 (61\%) of 160 surgically resceted, primary unifocal HCC specimens (Fig. 1A). Of these $160 \mathrm{HCCs}$, RNA samples of nontumorous liver were examined in 153 cases. In nontumorous liver, overexpression of Aurora $B$ mRNA at a moderate level was detected in 2 cases (1.3\%). We then examined Aurora $B$ gene expression in cell lines, and all 7 liver cancer cell lines showed high expression levels of Aurora $B$ mRNA, which correlated with protein levels (Fig. 1B).

\section{Clinicopathologic significance of Aurora B mRNA overexpression in hepatocellular carcinoma}

To elucidate the biologic significance of Aurora B in HCC, we correlated Aurora B expression with major clinicopathologic features of HCC. As shown in Table 1, Aurora $B$ overexpression was associated with high serum AFP level $(\geq 200 \mathrm{ng} / \mathrm{mL} ; P<0.0001)$, but not with age, gender, chronic hepatitis $\mathrm{B} / \mathrm{C}$ virus infection, or liver functional reserve (Child-Pugh class).

Histologically, Aurora B overexpression did not correlate with the presence of liver cirrhosis. Nevertheless, HCCs with Aurora B overexpression were associated with large tumor size ( $>5 \mathrm{~cm} ; P=0.021)$, high-grade histology $(P=$ $0.0007)$, and advanced tumor stage $(P<0.0001)$.

Genes for $p 53, \beta$-catenin, and Aurora $A$ are most frequently deregulated in HCC and are closely associated with HCC progression [7,11]. Therefore, relations between Aurora $B$ overexpression with mutations of $p 53$ and $\beta$-catenin and with Aurora $A$ overexpression were analyzed. Table 1 shows that Aurora $B$ overexpression was correlated with Aurora $A$ overexpression $(P=$ $0.0003)$ and $p 53$ mutation $(P=0.002)$. In contrast, Aurora $B$ was more frequently overexpressed in HCCs without $\beta$-catenin mutation $(P=0.002)$.

\section{Aurora $B$ overexpression predicts early tumor recurrence and poor prognosis}

HCC with Aurora B overexpression were associated with worse 5-year survival than HCC without Aurora B overexpression $(P<0.0001$; Table 1 and Fig. $2 A)$. Moreover, HCC with Aurora B overexpression showed more frequent ETR $(P<0.0001$; Table 1$)$, the most crucial clinical event associated with poor prognosis of HCC after hepatectomy $[6,19]$. As listed in Table 2, multivariate analysis showed that Aurora B overexpression (odds ratio $[\mathrm{OR}$ ], 4.679; $P=0.0011$, tumor size (OR, 3.735; $P$ $=0.0031)$, tumor stage (OR, 3.611; $P=0.0073)$, and age $\leq 55$ years (OR, 1.043; $P=0.0245)$ were significant independent risk factors by Cox's proportional hazards model for the occurrence of ETR. A conditional effect plot of age and Aurora B overexpression on ETR was drawn based on the multiple logistic regression model with fixed tumor size and stage (Fig. 2B). The probability of ETR was significantly higher in patients with HCC showing Aurora $B$ overexpression. Furthermore, ETR (OR, 29.181; $P<0.0001)$, tumor grade (OR, 1.516; $P=$ $0.0041)$, and tumor size (OR, 1.072; $P=0.0048$ ) were significant independent risk factors associated with poor patient survival (Table 2). Principally, we found that Aurora $B$ overexpression was an independent risk factor associated with high-stage tumor (OR, 7.439; $P=$ 0.0003; Table 2) and ETR (OR, 4.679; $P=0.0011$ ), hence contributing to poor patient survival. Nevertheless, Aurora $B$ overexpression did not exert prognostic effects for tumor size or tumor grade (Table 2).

\section{Interaction of Aurora B overexpression with Aurora $A$ overexpression and mutations of $p 53$ and $\beta$-catenin in hepatocellular carcinoma}

Because both Aurora A and Aurora B correlate closely with unfavorable prognosis of $\mathrm{HCC}$ and may be potential therapeutic targets $[11,12]$, we analyzed the possible interplay between these two important biomarkers. In this study, Aurora A overexpression, which was found in 100 (63\%) of 160 HCCs examined, significantly correlated with Aurora B overexpression $(P=0.0003$; Table 1). Moreover, as shown in Table $3, \mathrm{HCC}$ with overexpression of both Aurora A and Aurora B showed the highest occurrence of high serum AFP level ( $\geq 200 \mathrm{ng} /$ $\mathrm{mL} ; 71 \%$ ), large tumor size (> $5 \mathrm{~cm} ; 72 \%$ ), grade II to IV 


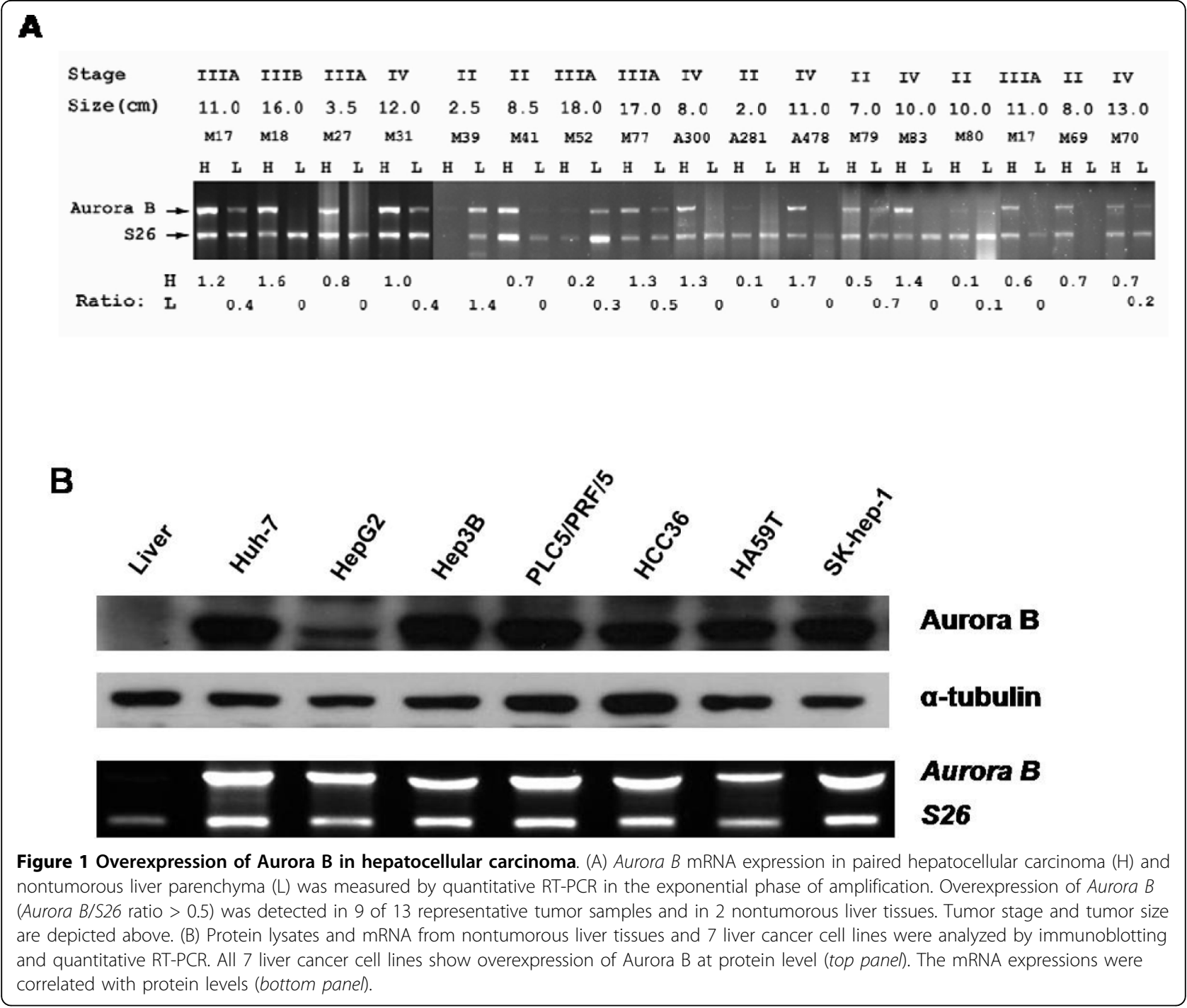

tumor (94\%), stage IIIA to IV tumor (82\%), p53 mutation (64\%), wild-type $\beta$-catenin (92\%), and the worst 5 year survival rate (19\%) than the other groups.

Because Aurora $B$ overexpression was correlated with Aurora $A$ overexpression $(P=0.0003), p 53$ mutation $(P$ $=0.002)$, and infrequent $\beta$-catenin mutation $(P=0.002)$ in this study (Table 1 ), we then analyzed the prognostic value of Aurora $B$ overexpression for patient survival in relation to Aurora $A$ overexpression and $p 53 / \beta$-catenin mutations. We showed that HCC with Aurora B overexpression was associated with worse 5-year survival regardless of Aurora $A$ expression status $(P=0.013$ for HCC without Aurora $A$ overexpression and $P=0.001$ for HCC with Aurora $A$ overexpression; Fig. 3A), $p 53$ mutation $(P=0.016$ in wild-type $p 53 \mathrm{HCC}$ and $P=$ 0.123 in $p 53$-mutated HCC; Fig. $3 \mathrm{~B})$, and $\beta$-catenin mutation $(P=0.329$ in $\beta$-catenin-mutated $\mathrm{HCC}$ and $P<$ 0.001 in wild-type $\beta$-catenin HCC; Fig. $3 \mathrm{C}$ ).
Anticancer effects of Aurora $B$ kinase selective inhibitor, AZD1152-HQPA, in HCC cells

The association of Aurora $B$ overexpression and tumor invasiveness of $\mathrm{HCC}$ prompted us to explore the effects of Aurora B kinase inhibition on HCC cell viability. Huh-7 and Hep3B cells were treated with increasing concentrations of an Aurora B selective small-molecule inhibitor, AZD1152-HQPA, for 72 hours. Concentration-dependent inhibitory effects of cell viability were observed in both cell lines (Fig. 4A). The ratios of viable Huh-7 and Hep3B cells consistently decreased with higher concentrations of AZD1152-HQPA. The 50\% inhibitory concentrations of cell viability $\left(\mathrm{IC}_{50}\right)$ at $72-\mathrm{hr}$ were $16.72 \pm 2.44 \mathrm{nM}$ and $4.79 \pm 1.03 \mathrm{nM}$ for Huh-7 and Hep3B, respectively (Fig. 4A). Aurora A autophosphorylation at T288 [29] and histone H3 phosphorylation at Ser10 [12] represent the activity of Aurora A and Aurora B, respectively. As shown in Fig. 4B, AZD1152- 
Table 1 Correlation of Aurora B mRNA expression with clinicopathologic and molecular features in 160 patients with primary unifocal HCC by univariate logistic regression analyses

\begin{tabular}{|c|c|c|c|c|}
\hline \multirow[t]{2}{*}{ Feature } & \multicolumn{4}{|c|}{ Aurora $B$ overexpression } \\
\hline & Total & $n(\%)$ & OR $(95 \% \mathrm{Cl})^{*}$ & $P$ value \\
\hline \multicolumn{5}{|l|}{ Age } \\
\hline$>55$ & 88 & $49(56)$ & 1.0 & \\
\hline$\leq 55$ & 72 & $49(68)$ & $1.7(0.89-3.25)$ & 0.11 \\
\hline \multicolumn{5}{|l|}{ Gender } \\
\hline Female & 38 & $23(61)$ & 1.0 & \\
\hline Male & 122 & $75(61)$ & $1.04(0.49-2.19)$ & 0.916 \\
\hline \multicolumn{5}{|l|}{$\mathrm{HBsAg}$} \\
\hline Negative & 53 & $27(51)$ & 1.0 & \\
\hline Positive & 107 & $71(66)$ & $1.9(0.97-3.72)$ & 0.06 \\
\hline \multicolumn{5}{|l|}{ Anti-HCV } \\
\hline Negative & 100 & $68(68)$ & 1.0 & \\
\hline Positive & 53 & $30(57)$ & $0.8(0.41-1.57)$ & 0.517 \\
\hline \multicolumn{5}{|l|}{ AFP } \\
\hline$<200$ & 80 & $33(41)$ & 1.0 & \\
\hline$\geq 200$ & 80 & $65(81)$ & $6.17(3.01-12.63)$ & $<0.0001$ \\
\hline \multicolumn{5}{|l|}{ Child-Pugh } \\
\hline A & 147 & $93(63)$ & 1.0 & \\
\hline B & 11 & $5(45)$ & $0.48(0.14-1.66)$ & 0.24 \\
\hline \multicolumn{5}{|l|}{ Cirrhosis } \\
\hline No & 99 & $66(67)$ & 1.0 & \\
\hline Yes & 61 & $32(52)$ & $0.55(0.29-1.06)$ & 0.073 \\
\hline \multicolumn{5}{|l|}{ Size $(\mathrm{cm})$} \\
\hline$\leq 5$ & 72 & $37(51)$ & 1.0 & \\
\hline$>5$ & 88 & $61(69)$ & $2.14(1.12-4.08)$ & 0.021 \\
\hline \multicolumn{5}{|l|}{ Grade } \\
\hline I & 31 & $10(32)$ & 1.0 & \\
\hline$\|$ & 74 & $48(65)$ & $3.88(1.59-9.46)$ & \\
\hline III-IV & 55 & $40(73)$ & $5.6(2.15-14.61)$ & 0.0007 \\
\hline \multicolumn{5}{|l|}{ Stage } \\
\hline$|-| \mid$ & 66 & $21(32)$ & 1.0 & \\
\hline IIIA-IV & 94 & $77(82)$ & $9.71(4.64-20.3)$ & $<0.0001$ \\
\hline \multicolumn{5}{|l|}{ ETR† } \\
\hline No & 76 & $28(37)$ & 1.0 & \\
\hline Yes & 73 & $61(84)$ & $8.71(4.02-18.91)$ & $<0.0001$ \\
\hline \multicolumn{5}{|l|}{ 5-year survival } \\
\hline Yes & 56 & $22(39)$ & 1.0 & \\
\hline No & 104 & $76(73)$ & $4.19(2.11-8.36)$ & $<0.0001$ \\
\hline \multicolumn{5}{|c|}{ Aurora A overexpression } \\
\hline No & 60 & $26(43)$ & 1.0 & \\
\hline Yes & 100 & $72(72)$ & $3.36(1.72-6.58)$ & 0.0003 \\
\hline \multicolumn{5}{|l|}{ p53 mutation } \\
\hline No & 68 & $34(50)$ & 1.0 & \\
\hline Yes & 66 & $50(76)$ & $3.13(1.5-6.53)$ & 0.002 \\
\hline \multicolumn{5}{|c|}{$\beta$-catenin mutation } \\
\hline No & 128 & $85(66)$ & 1.0 & \\
\hline Yes & 22 & $7(32)$ & $0.24(0.09-0.62)$ & 0.002 \\
\hline
\end{tabular}

*OR: odds ratio; $\mathrm{Cl}$ : confidence interval

tETR: early tumor recurrence within 12 months after surgery 


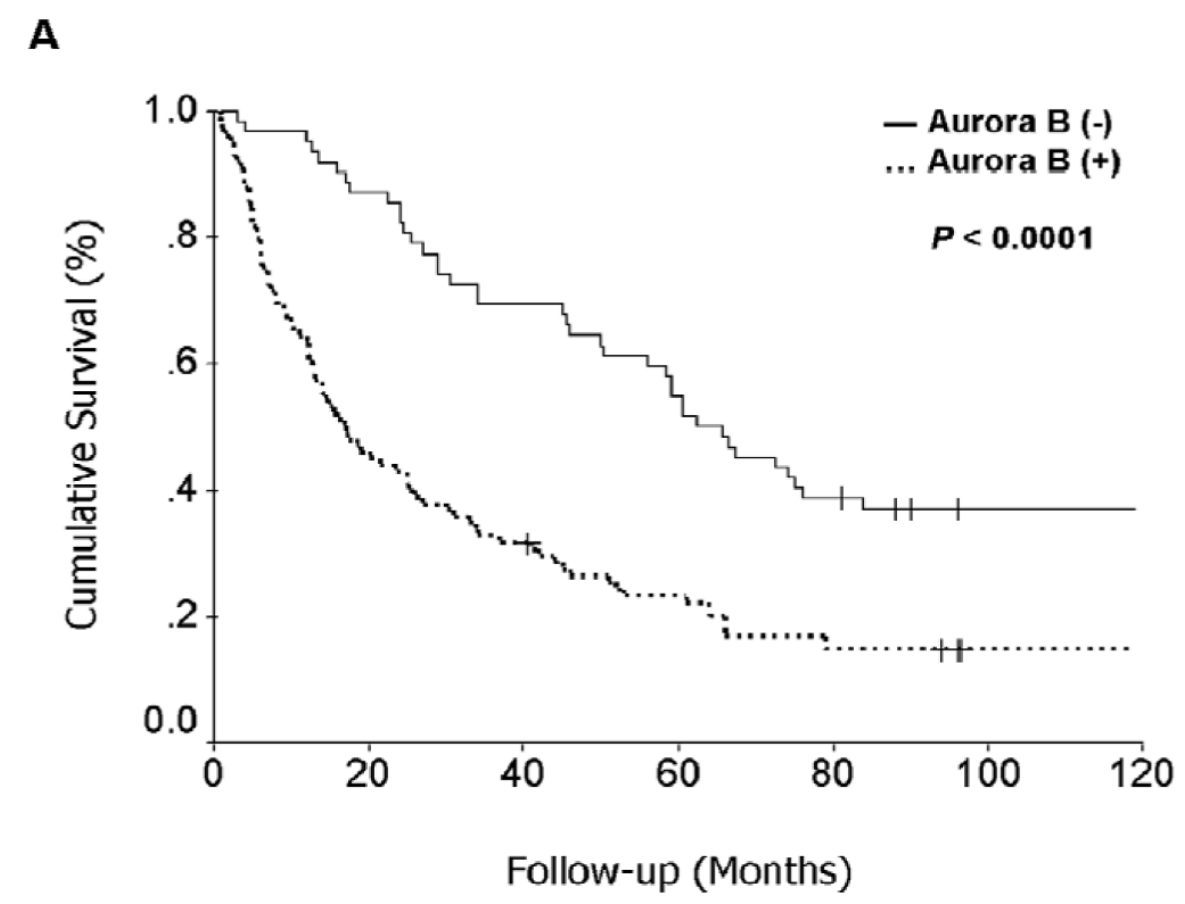

$\mathbf{B}$

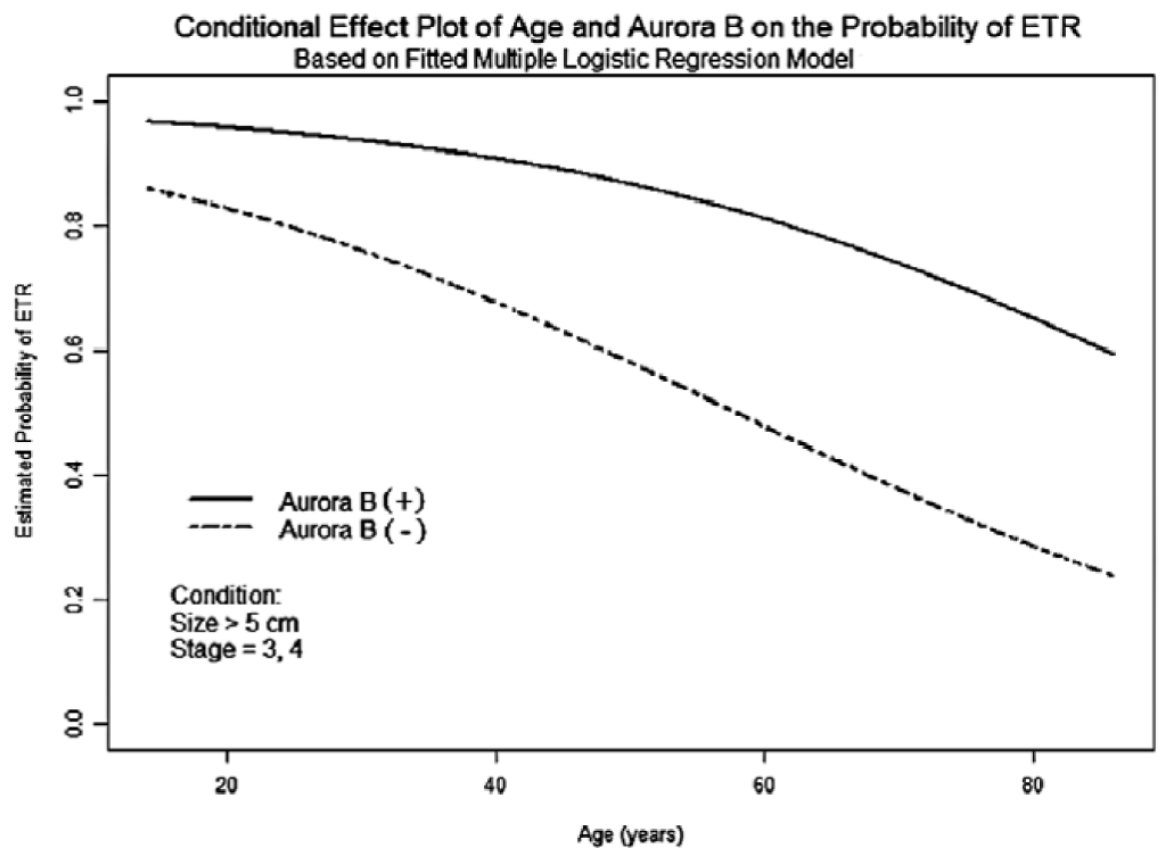

Figure 2 Aurora B overexpression predicts early tumor recurrence and poor prognosis. (A) Cumulative survival curve for 160 patients with primary unifocal hepatocellular carcinoma (HCC). HCC with Aurora B mRNA overexpression, designated Aurora B (+), had significantly worse 5year survival than HCC without Aurora B mRNA overexpression, designated Aurora B (-). (B) Conditional effect plot of age on ETR with or without overexpression of Aurora $B$ mRNA. Based on multiple logistic regression model $(n=149)$. The other independent variables were fixed as size $>5 \mathrm{~cm}$ and stage III-IV. 
Table 2 Multivariate analyses of the risk factors associated with ETR, tumor size, tumor stage, tumor grade, and survival of the patients with primary unifocal HCC

\begin{tabular}{|c|c|c|c|c|c|}
\hline Covariate & $\begin{array}{l}\text { Variable } \\
\text { Estimate }\end{array}$ & SE & Wald $\chi^{2}$ & $P$ & OR \\
\hline \multicolumn{6}{|l|}{$\overline{\text { ETR } \text { (yes) }}{ }^{\mathbf{a}}$} \\
\hline Intercept & -0.2071 & 1.1146 & 0.0345 & 0.8526 & - \\
\hline $\begin{array}{l}\text { Aurora B } \\
\uparrow^{*}\end{array}$ & 1.543 & 0.4721 & 10.6826 & 0.0011 & 4.679 \\
\hline Size & 1.3177 & 0.4451 & 8.7658 & 0.0031 & 3.735 \\
\hline Stage & 1.2839 & 0.4789 & 7.1876 & 0.0073 & 3.611 \\
\hline Age $\leq 55$ & 0.0414 & 0.0184 & 5.0581 & 0.0245 & 1.043 \\
\hline \multicolumn{6}{|l|}{ Size $^{b}$} \\
\hline Intercept & -0.7535 & 0.4762 & 2.5037 & 0.1136 & - \\
\hline $\begin{array}{l}\text { p53 } \\
\text { mutation }\end{array}$ & 1.5197 & 0.4828 & 9.9073 & 0.0016 & 4.571 \\
\hline $\begin{array}{l}\text { Aurora A } \\
\uparrow\end{array}$ & 1.1577 & 0.4937 & 5.48 & 0.0192 & 3.176 \\
\hline $\mathrm{HCV}$ & -1.0277 & 0.4958 & 4.2961 & 0.0382 & 0.358 \\
\hline Cirrhosis & -1.1187 & 0.4989 & 5.0291 & 0.0249 & 0.327 \\
\hline \multicolumn{6}{|l|}{ Stage III-IV c } \\
\hline Intercept & -4.3949 & 1.1039 & 15.8508 & $<0.0001$ & - \\
\hline $\begin{array}{l}\text { Aurora B } \\
\uparrow\end{array}$ & 2.0067 & 0.5516 & 13.2351 & 0.0003 & 7.439 \\
\hline $\begin{array}{l}\text { p53 } \\
\text { mutation }\end{array}$ & 1.0769 & 0.5399 & 3.9782 & 0.0461 & 2.936 \\
\hline Grade & 1.0442 & 0.3965 & 6.9351 & 0.0085 & 2.841 \\
\hline Size & 0.2495 & 0.0755 & 10.9173 & 0.001 & 1.283 \\
\hline \multicolumn{6}{|l|}{ Grade $^{d}$} \\
\hline Intercept & 0.4449 & 0.4037 & 1.2146 & 0.2704 & - \\
\hline HBV & 0.8776 & 0.3814 & 5.2947 & 0.0214 & 2.405 \\
\hline $\begin{array}{l}\text { p53 } \\
\text { mutation }\end{array}$ & 0.8058 & 0.3677 & 4.8033 & 0.0284 & 2.239 \\
\hline AFP & 0.8056 & 0.3808 & 4.4754 & 0.0344 & 2.238 \\
\hline $\begin{array}{l}\beta \text {-catenin } \\
\text { mutation }\end{array}$ & -1.4923 & 0.5578 & 7.1569 & 0.0075 & 0.225 \\
\hline \multicolumn{6}{|l|}{ Survival time } \\
\hline ETR & 3.3735 & 0.5685 & 35.2186 & $<0.0001$ & 29.181 \\
\hline Grade & 0.4158 & 0.1448 & 8.2453 & 0.0041 & 1.516 \\
\hline Size & 0.0698 & 0.0247 & 7.9621 & 0.0048 & 1.072 \\
\hline
\end{tabular}

aLogistic regression model: $n=149$, percentage of concordant pairs $=86.5 \%$, percentage of discordant pairs $=13.3 \%$, adjusted generalized $R^{2}=0.3755$, Hosmer and Lemeshow goodness-of-fit test $P=0.4583$ (degrees of freedom $=8$ ). bLogistic regression model: $n=120$, percentage of concordant pairs $=84.3 \%$, percentage of discordant pairs $=14.4 \%$, adjusted generalized $R^{2}=0.3507$, Hosmer and Lemeshow goodness-of-fit test $P=0.3603$ (degrees of freedom $=8$ ). 'Logistic regression model: $n=125$, percentage of concordant pairs $=90.9 \%$, percentage of discordant pairs $=8.9 \%$, adjusted generalized $R^{2}=0.4647$, Hosmer and Lemeshow goodness-of-fit test $P=0.7933$ (degrees of freedom $=8$ ).

HQPA induced dephosphorylation of histone H3 (Ser10) in a concentration-dependent manner, while the phosphorylation level of Aurora A (T288) did not change. The data suggest that AZD1152-HQPA exerts its anticancer effects in $\mathrm{HCC}$ cells through the inhibition of Aurora B.
Because Aurora kinase inhibitors have been shown to induce cell death after the cell cycle has been disturbed [10]. We therefore investigated the effects of AZD1152HQPA on HCC cell cycle progression and apoptosis. As shown in Fig. 5A, AZD1152-HQPA treatment resulted in accumulation of Hep3B cells with 4N DNA contents at 24-h, followed by the appearance of cells with $8 \mathrm{~N}$ DNA contents at 48-h. Our data demonstrated that AZD1152-HQPA induced cell cycle disturbance in a concentration-dependent manner (Fig. 5A). We also examined the ability of AZD1152-HQPA to induce apoptosis in HCC cells. As shown in Fig. 5B, AZD 1152-HQPA induced concentration-dependent apoptosis in both Huh-7 and Hep3B cells. After 48 hours of treatment with AZD1152-HQPA above $25 \mathrm{nM}$, the sub-G1 fractions of Huh-7 cells and Hep3B cells significantly increased $(P<0.01)$. In Fig. 5B, AZD1152-HQPA induced apoptosis more efficiently in Hep3B cells, which is in accordance with the antiproliferative effects.

\section{Discussion}

In mammals, there are three highly related Aurora kinases: Aurora A, B, and C. These 3 closely related kinases share a high degree of sequence homology in their catalytic domains [30]. Despite the sequence homology and common association with mitotic regulatory events, the subcellular localization and signaling substrates differ, and hence the functions of Aurora A and Aurora $B$ are essentially distinct [13]. We have reported that Aurora A is highly expressed in HCC and that overexpression is closely associated with aggressive tumor phenotypes and worse patient prognosis [11], but the clinicopathologic significance of Aurora B in HCC progression remains to be clarified. In this study, we demonstrated that overexpression of Aurora A and Aurora $B$ was detected in $63 \%$ and $61 \%$ of 160 surgically resected, primary unifocal HCCs, respectively. Importantly, Aurora B mRNA expression correlated with major clinicopathologic parameters related to tumor progression by univariate analyses, including high AFP level $(P<0.0001)$, large tumor size $(P=0.021)$, higher tumor grade $(P=0.0007)$, and higher tumor stage $(P<$ 0.0001). By multivariate analyses, we showed that Aurora $B$ overexpression was associated with high-stage (stages IIIA, IIIB, and IV) HCC, which exhibits vascular invasion and various extent of microscopic intrahepatic spread (OR, 7.439; $P=0.0003)$. These findings suggest that overexpression of Aurora $B$ is associated with tumor invasion and intrahepatic metastasis of HCC, as having been shown in Aurora A [11].

Although the diagnosis and management of HCC have progressed significantly, the prognosis for patients receiving surgical treatment remains poor because of the high ETR $[6,31]$. Hence, the identification of molecular factors 
Table 3 Cooperations of Aurora B and Aurora A mRNA expressions in relation to clinicopathologic and molecular features in 160 patients with primary unifocal HCC

\begin{tabular}{|c|c|c|c|c|c|}
\hline \multirow[t]{2}{*}{ Feature } & \multicolumn{4}{|c|}{ Aurora B / Aurora A expression number (\%) } & \multirow[t]{2}{*}{$P$ value } \\
\hline & $+/+(n=72)$ & $+/-(n=26)$ & $-/+(n=28)$ & $-/-(n=34)$ & \\
\hline AFP & & & & & $<0.0001$ \\
\hline$<200$ & $21(29)$ & $12(46)$ & $18(64)$ & $29(85)$ & \\
\hline$\geq 200$ & $51(71)$ & $14(54)$ & $10(36)$ & $5(15)$ & \\
\hline Size $(\mathrm{cm})$ & & & & & $<0.0001$ \\
\hline$\leq 5$ & $20(28)$ & $17(65)$ & $11(39)$ & $24(71)$ & \\
\hline$>5$ & $52(72)$ & $9(35)$ & $17(61)$ & $10(29)$ & \\
\hline Grade & & & & & 0.0014 \\
\hline । & $4(6)$ & $6(23)$ & $8(29)$ & $13(38)$ & \\
\hline$\|$ & $36(50)$ & $12(46)$ & $10(36)$ & $16(47)$ & \\
\hline III-IV & $32(44)$ & $8(31)$ & $10(36)$ & $5(15)$ & \\
\hline Stage & & & & & $<0.0001$ \\
\hline$|-| \mid$ & $13(18)$ & $8(31)$ & $16(57)$ & $29(85)$ & \\
\hline IIIA-IV & $59(82)$ & $18(69)$ & $12(43)$ & $5(15)$ & \\
\hline p53 mutation & & & & & 0.0099 \\
\hline No & $22(36)$ & $12(52)$ & $15(65)$ & $19(70)$ & \\
\hline Yes & $39(64)$ & $11(48)$ & $8(35)$ & $8(30)$ & \\
\hline$\beta$-catenin mutation & & & & & 0.0024 \\
\hline No & $61(92)$ & $24(92)$ & $23(85)$ & $20(65)$ & \\
\hline Yes & $5(8)$ & $2(8)$ & $4(15)$ & $11(35)$ & \\
\hline ETR & & & & & $<0.0001$ \\
\hline No & $17(26)$ & $11(46)$ & $19(70)$ & $29(88)$ & \\
\hline Yes & $48(74)$ & $13(54)$ & $8(30)$ & $4(12)$ & \\
\hline 5-year survival & & & & & 0.0003 \\
\hline Yes & $14(19)$ & $8(31)$ & $15(54)$ & $19(56)$ & \\
\hline No & $58(81)$ & $18(69)$ & $13(46)$ & $15(44)$ & \\
\hline
\end{tabular}

Abbreviation: +, present; -, absent

to predict ETR will help develop better strategies for patient management. Here, we showed that HCC with Aurora $B$ overexpression had a greater than 2 -fold higher chance of ETR than HCC without the overexpression (OR, 8.71; 95\% confidence interval [CI], 4.02-18.91; $P<$ 0.0001 ). Consistent with its association with high-stage HCC and frequent ETR, HCC with Aurora B overexpression showed worse 5 -year survival than those without the overexpression (OR, 4.19; 95\% CI, 2.11-8.36; $P<0.0001)$. The multivariate analysis confirmed that Aurora $B$ overexpression was an independent risk factor associated with ETR (OR, 4.679; $P=0.0011$; Table 2). These findings are consistent with the correlation of Aurora B overexpression with poor tumor differentiation and worse patient survival in thyroid [32], prostate [33], and hepatobiliary cancers $[34,35]$. Taken together, our findings suggest that Aurora $B$ overexpression serves as a useful marker predicting ETR and hence poor prognosis.

In the present study, we showed that the expression of Aurora $B$ and Aurora $A$ were closely correlated $(P=0.0003$; Table 1$)$ and exhibited an interaction contributing to HCC progression. HCC with overexpression of both kinases exhibited the highest rates of high AFP level (71\%), vascular invasion (stage IIIA-IV; $82 \%$ ), and ETR (74\%), 4-fold higher than those without overexpression of either kinase $(15 \%, 15 \%$, and $12 \%$, respectively). Consistently, HCC with overexpression of both kinases showed the lowest 5-year survival (19\%), approximately one-third of those without any overexpression (56\%). Our findings suggest that Aurora A and Aurora B contribute cooperatively to a more malignant HCC phenotype, ETR, and poor prognosis.

$\mathrm{HCC}$ has been classified into two major groups according to chromosomal stability status [36]; tumors characterized by chromosomal instability were associated with more $p 53$ mutation and less $\beta$-catenin mutation, the two major genetic mutations in human HCC $[17,24,25]$. Mutation of $p 53$ correlated with aggressive HCC and poor prognosis [24,25], whereas $\beta$-catenin mutation was associated with less tumor aggression and more favorable prognosis [17]. We also showed that Aurora A overexpression correlated positively with $p 53$ mutation and inversely with $\beta$-catenin mutation [11]. In the present study, we showed that 
A

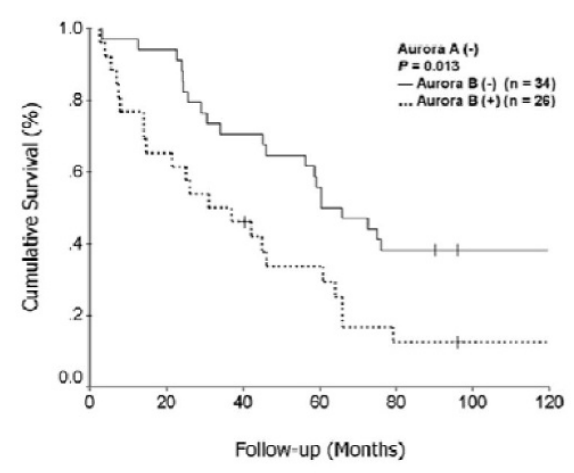

B

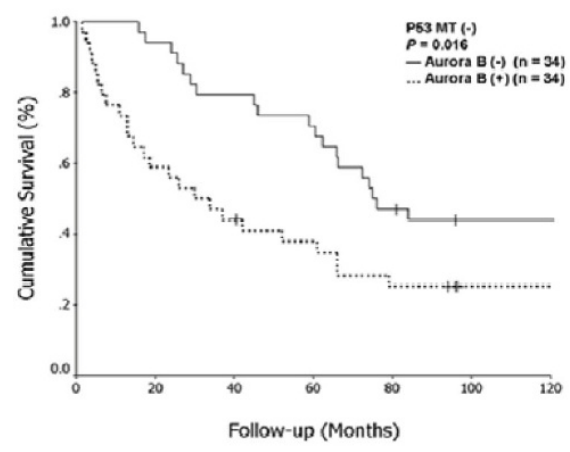

C

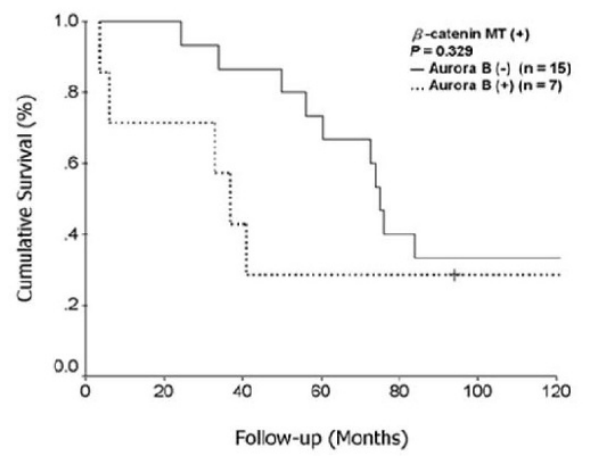

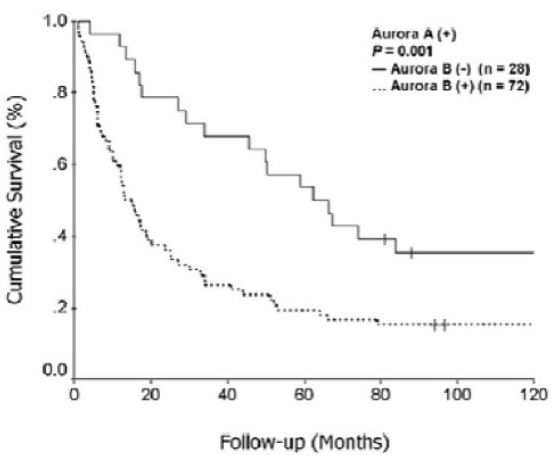
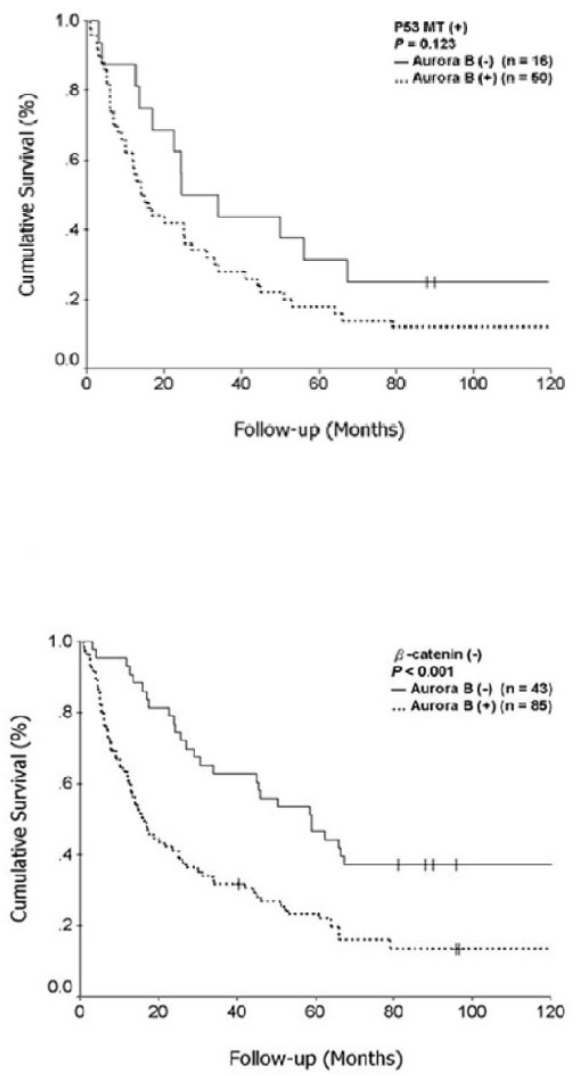

Figure 3 Cumulative survival curve for HCC in relation to increased or normal expression of Aurora $B$ and the presence or absence of Aurora A overexpression (A), p53 mutation (B), and $\beta$-catenin mutation (C).

Aurora $B$ overexpression positively correlated with $p 53$ mutation $(P=0.002)$ and inversely with $\beta$-catenin mutation $(P=0.002)$. Despite the association with these important molecular factors, Aurora B overexpression predicted worse 5-year survival regardless of Aurora $A$ expression status, $p 53$ mutation, or $\beta$-catenin mutation (Fig. 3). Hence, it is suggested that Aurora B overexpression, independent of Aurora $A$ overexpression and $p 53 / \beta$-catenin mutations, is an important molecular factor associated with vascular invasion, leading to high-stage tumor, ETR, and poor prognosis for patients with surgically resected HCC.

Since the discovery of Aurora kinases, Aurora A has attracted much attention as an appealing therapeutic 
A

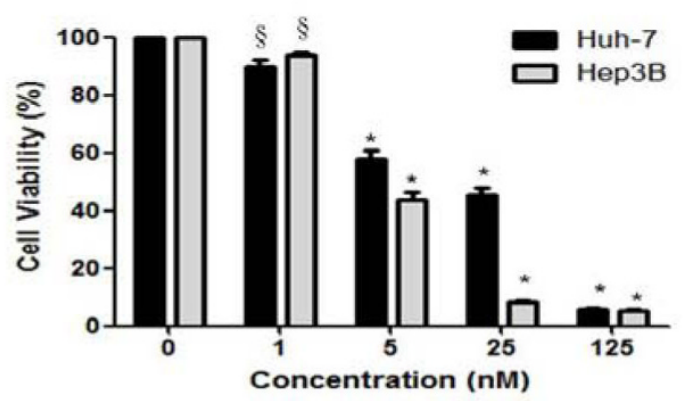

Huh-7
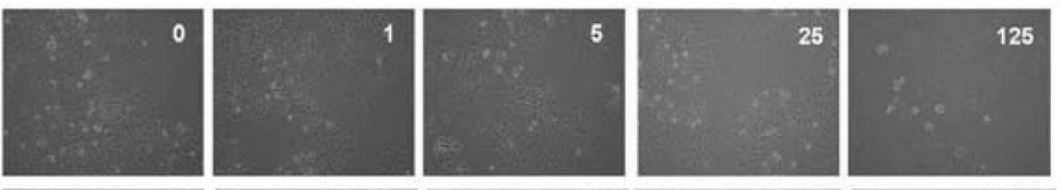

Hep3B
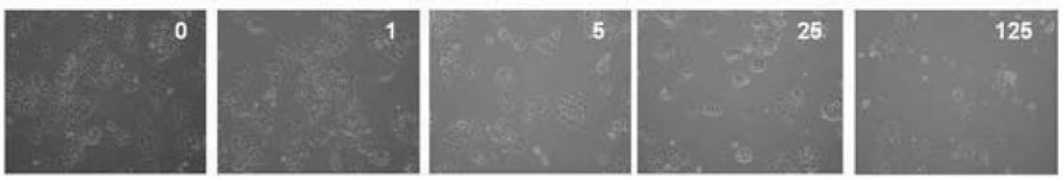

B

AZD1152-HQPA for 24 hours

\begin{tabular}{lllll}
\hline $\mathrm{C}$ & 1 & 5 & 25 & 125
\end{tabular}

Phospho-histone H3

Phospho-Aurora A (T288)

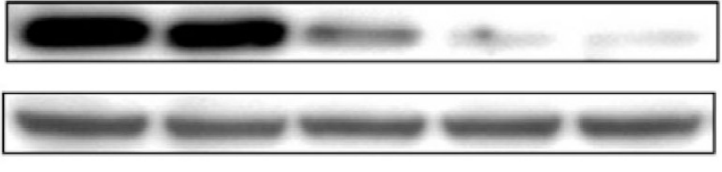

Aurora A

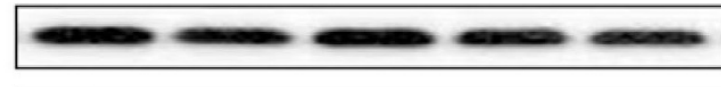

Aurora B

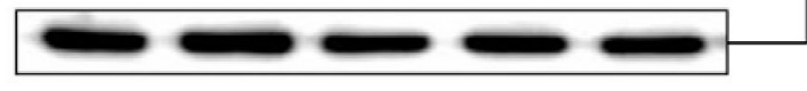

Phospho-histone $\mathrm{H} 3$

Phospho-Aurora A (T288)
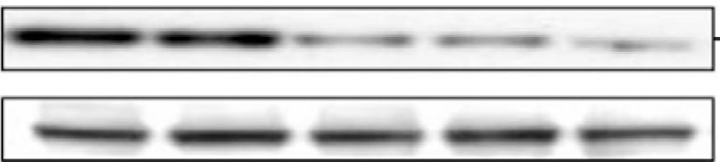

\section{Aurora A \\ Aurora B}
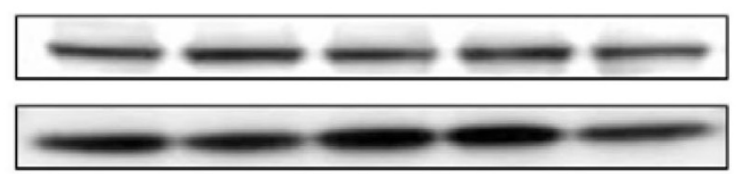

Hep3B

Figure 4 Aurora B kinase selective inhibitor, AZD1152-HQPA, shows antiproliferative effects in HCC cells. (A) Concentration-dependent inhibitory effects of AZD1152-HQPA on cell viability in Huh-7 and Hep3B cell lines. Cells were treated with AZD1152-HQPA at 1, 5, 25, and 125 $\mathrm{nM}$ in 10\% FBS-supplemented medium for 72 hours; cell viability was determined by trypan blue assay. Columns: means; bars: SD ( $n=3)$. $\S, p<$ $0.05 ; *, p<0.01$ (compared with untreated controls). The changes in cell counts and morphologic features are shown in the lower panels (magnification, $\times 100$ ). (B) Huh-7 and Hep3B cells were treated with AZD1152-HQPA for 24 hours. The cell lysates were then immunoblotted. Histone H3 (Ser10) phosphorylation, the key substrate of Aurora B signaling, was downregulated in a concentration-dependent manner. Aurora A (T288) phosphorylation, the key substrate of Aurora A signaling, was not repressed by AZD1152-HQPA treatments. 

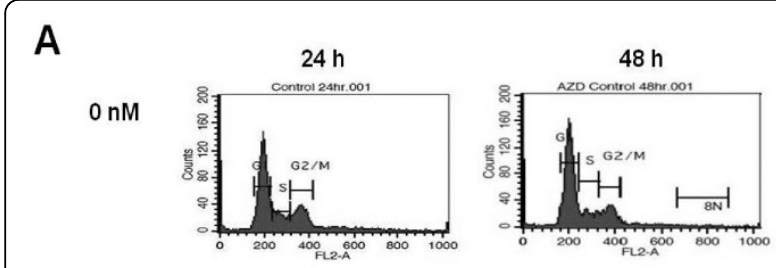

$5 \mathrm{nM}$
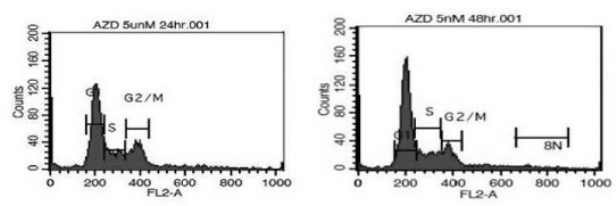

$25 \mathrm{nM}$
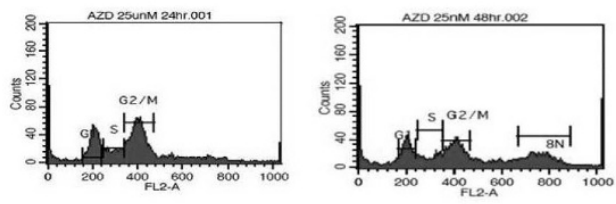

$125 \mathrm{nM}$
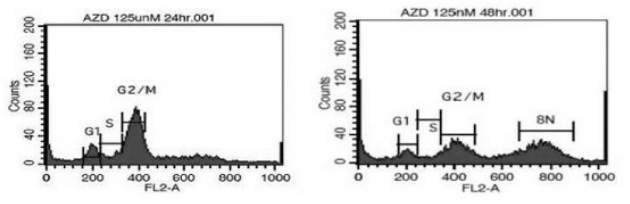

B

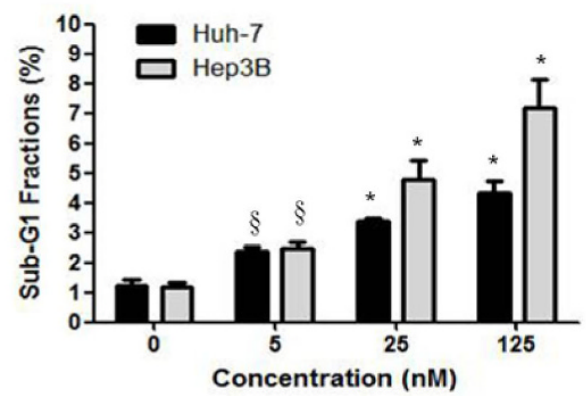

Figure 5 AZD1152-HQPA treatment leads to cell cycle arrest, accumulation of cells with $\geq 4 \mathrm{~N}$ DNA content, and apoptosis in HCC cells. (A) Hep3B cells were treated with vehicle or AZD1152HQPA at 5, 25, and $125 \mathrm{nM}$ for 24 to 48 hours, and then stained with propidium iodide. DNA contents were analyzed by flow cytometry. Data shown are representative of three independent experiments. (B) Percentage of sub-G1 DNA contents in Huh-7 and Hep3B cells treated with vehicle or AZD1152-HQPA at 5, 25, and 125 nM for 48 hours. Columns: means; bars: SD $(n=3)$. $\S, p<0.05$; *, $p<0.01$ (compared to untreated controls).

target because of its oncogenic potential [37], and the frequent overexpression of Aurora A in a variety of human cancers [38]. However, subsequent pharmacologic studies demonstrated that dual Aurora A and Aurora $B$ kinase inhibitors produced biologic responses equivalent to Aurora B disruption alone [10], suggesting that Aurora B is a critical therapeutic target for cancer. We previously reported that a novel dual Aurora A and Aurora B kinase inhibitor, VE-465, had anticancer effects in human HCC [12]. Hence, determining whether Aurora A or Aurora B is the pertinent therapeutic target for HCC is imperative. In the present study, we first showed that Aurora B overexpression was associated with major clinical (high AFP, ETR) and histopathologic (large tumor, higher tumor grade, and higher tumor stage) features, which are critical for tumor progression of HCC, and hence is an independent risk factor for poor prognosis of patients with surgically resected HCC. In addition, we showed AZD1152-HQPA, an Aurora B selective inhibitor, has anticancer effects in HCC cells. AZD1152-HQPA treatment resulted in profound inhibition of Aurora B signaling, which in turn led to cell cycle disturbance, apoptosis, and growth suppression in HCC cells. Our results suggest that Aurora B selective inhibitors are potential drugs for HCC treatment, confirming the observation that AZD1152 is a novel promising therapeutic approach for HCC [39]. Nevertheless, whether targeting Aurora B kinase alone is a better therapeutic strategy, compared with the targeting of both Aurora A and Aurora B kinases, will require further exploration.

\section{Conclusion}

In this study, we showed frequent overexpression of Aurora $B$ in HCC, which was closely associated with aggressive tumor phenotypes. Aurora $B$ overexpression, independent of Aurora $A$ overexpression and $p 53 / \beta$ catenin mutations, is an important molecular marker associated with early recurrence and poor prognosis. Besides, an Aurora B kinase selective inhibitor, AZD1152-HQPA, had anticancer effects in HCC cells. These findings indicate the importance of Aurora B kinase in HCC progression and as a potential therapeutic target for HCC.

\section{Abbreviations}

HCC: hepatocellular carcinoma; AFP: $\alpha$-fetoprotein; ETR: early tumor recurrence; RT-PCR: reverse transcription-polymerase chain reaction; OR: odds ratio.

\section{Acknowledgements \\ Grant support: \\ Grant NSC96-2628-B-002-054-MY3 from the National Science Council (Taiwan), Grant DOH97-TD-B-111-001 from the Department of Health (Taiwan), and Grant NSC98-3112-B-075A-001 from the National Science Council (Taiwan). \\ We thank Ms. Chia-Chi Cheng (National Taiwan University Hospital) for assistance in statistical computing.}

\section{Author details}

${ }^{1}$ Departments of Oncology, National Taiwan University Hospital Yun-Lin Branch, No. 360, Singjhong Village, Huwei Township, Yun-Lin County, 63252, Taiwan. ${ }^{2}$ National Center of Excellence for Clinical Trial and Research, National Taiwan University Hospital, No. 7, Chung-Shan S. Rd., Taipei, 10016, Taiwan. ${ }^{3}$ Department of Pathology, National Taiwan University Hospital, No. 7, Chung-Shan S. Rd., Taipei, 10016, Taiwan. ${ }^{4}$ Department of Medical Research, National Taiwan University Hospital, No. 7, Chung-Shan S. Rd., Taipei, 10016, Taiwan. ${ }^{5}$ Department of Surgery, National Taiwan University 
Hospital, No. 7, Chung-Shan S. Rd., Taipei, 10016, Taiwan. ${ }^{6}$ Department of Oncology, National Taiwan University Hospital, No. 7, Chung-Shan S. Rd., Taipei, 10016, Taiwan. ${ }^{7}$ Department of Internal Medicine, National Taiwan University Hospital, No. 7, Chung-Shan S. Rd., Taipei, 10016, Taiwan. ${ }^{8}$ Graduate Institute of Oncology, National Taiwan University College of Medicine, No.1, Jen-Ai Rd. Section 1, Taipei, 10051, Taiwan.

\section{Authors' contributions}

ZZL has made substantial contributions to conception, experimental design, data analysis, and manuscript writing of this study. YMJ conceived and designed the study. FCH was responsible for the statistical analysis. HWP participated in the experimental design. HWT performed the RT-PCR. PLL performed analysis of $p 53$ and $\beta$-catenin mutations. PHL supplied tissue samples and collected clinical data. ALC and HCH participated the conception and design of the study, guided the data analysis, manuscript preparation, and reviewed the manuscript. All authors read and approved the final manuscript.

\section{Competing interests}

The authors declare that they have no competing interests.

Received: 5 April 2010 Accepted: 28 August 2010

Published: 28 August 2010

\section{References}

1. Chen CJ, You SL, Lin LH, Hsu WL, Yang YW: Cancer epidemiology and control in Taiwan: a brief review. Jpn JClin Oncol 2002, 32:S66-81.

2. El-Serag HB: Hepatocellular carcinoma: an epidemiologic view. J Clin Gastroenterology 2002, 35:572-78.

3. Befeler AS, Di Bisceglie AM: Hepatocellular carcinoma: diagnosis and treatment. Gastroenterology 2002, 122:1609-1619.

4. Parkin DM, Bray F, Ferlay J, Pisani P: Global cancer statistics 2002. CA Cancer J Clin 2005, 55:74-108

5. Llovet JM, Bruix J: Novel advancements in the management of hepatocellular carcinoma in 2008. J Hepatol 2008, 48:S20-37.

6. Pan HW, Peng SY, Liu SH, Lai PL, Lee PH, Sheu JC, Chen CL, Hsu HC: Overexpression of osteopontin is associated with intrahepatic metastasis, early recurrence, and poorer prognosis of surgically resected hepatocellular carcinoma. Cancer 2003, 98:119-127.

7. El-Serag HB, Rudolph KL: Hepatocellular Carcinoma: Epidemiology and Molecular Carcinogenesis. Gastroenterology 2007, 132:2557-2576.

8. Kim GJ, Cho SJ, Won NH, Sung JM, Kim H, Chun YH, Park SH: Genomic imbalances in Korean hepatocellular carcinoma. Cancer Genet Cytogenet 2003, 142:129-133.

9. Wilkens L, Flemming P, Gebel M, Bleck J, Terkamp C, Wingen L, Kreipe H, Schlegelberger $B$ : Induction of aneuploidy by increasing chromosomal instability during dedifferentiation of hepatocellular carcinoma. Proc Natl Acad Sci USA 2004, 101(5):1309-1314.

10. Keen N, Taylor S: Aurora-kinase inhibitors as anticancer agents. Nat Rev Cancer 2004, 4(12):927-936.

11. Jeng $Y M$, Peng $S Y$, Lin CY, Hsu HC: Overexpression and amplification of Aurora-A in hepatocellular carcinoma. Clin Cancer Res 2004, 10(6):2065-2071.

12. Lin ZZ, Hsu HC, Hsu CH, Yeh PY, Huang CY, Huang YF, Chen TJ, Kuo SH, Hsu C, Hu FC, Jeng YM, Chung Y, Cheng AL: The Aurora kinase inhibitor VE-465 has anticancer effects in pre-clinical studies of human hepatocellular carcinoma. J Hepatol 2009, 50(3):518-527.

13. Gautschi O, Heighway J, Mack PC, Purnell PR, Lara PN, Gandara DR: Aurora Kinases as Anticancer Drug Targets. Clin Cancer Res 2008, 14(6):1639-1648.

14. Marumoto T, Zhang D, Saya H: Aurora-A - a guardian of poles. Nat Rev Cancer 2005, 5:42-50

15. Ruchaud S, Carmena M, Earnshaw WC: Chromosomal passengers: conducting cell division. Nat Rev Mol Cell Biol 2007, 8(10):798-812.

16. Girdler F, Gascoigne KE, Eyers PA, Hartmuth S, Crafter C, Foote KM, Keen NJ, Taylor SS: Validating Aurora B as an anti-cancer drug target. J Cell Sci 2006, 119(Pt 17):3664-3675.

17. Hsu HC, Jeng YM, Mao TL, Chu JS, Lai PL, Peng SY: B-catenin mutations are associated with a subset of low-stage hepatocellular carcinoma negative for hepatitis B virus and with favorable prognosis. Am J Pathol 2000, 157(3):763-770.
18. Hsu HC, Chiou TJ, Chen JY, Lee CS, Lee PH, Peng SY: Clonality and clonal evolution of hepatocellular carcinoma with multiple nodules. Hepatology 1991, 13:923-928.

19. Yuan RH, Jeng YM, Pan HW, Hu FC, Lai PL, Lee PH, Hsu HC: Overexpression of KIAA0101 predicts high stage, early tumor recurrence, and poor prognosis of hepatocellular carcinoma. Clin Cancer Res 2007, 13(18):5368-5376.

20. Peng SY, Chen WJ, Lai PL, Jeng YM, Sheu JC, Hsu HC: High alphafetoprotein level correlates with high stage, early recurrence and poor prognosis of hepatocellular carcinoma: significance of hepatitis virus infection, age, p53 and beta-catenin mutations. Int J Cancer 2004, 112(1):44-50.

21. Hsu HC, Wu TT, Wu MZ, Sheu JC, Lee CS, Chen DS: Tumor invasiveness and prognosis in resected hepatocellular carcinoma. Clinical and pathogenetic implications. Cancer 1988, 61(10):2095-2099.

22. Liu SH, Lin CY, Peng SY, Jeng YM, Pan HW, Lai PL, Liu CL, Hsu HC: Downregulation of annexin A10 in hepatocellular carcinoma is associated with vascular invasion, early recurrence, and poor prognosis in synergy with p53 mutation. Am J Pathol 2002, 160(5):1831-1837.

23. Vincent S, Marty L, Fort P: S26 ribosomal protein RNA: an invariant control for gene regulation experiments in eukaryotic cells and tissues. Nucleic Acids Res 1993, 21:1498.

24. Hsu HC, Tseng HJ, Lai PL, Lee PH, Peng SY: Expression of p53 gene in 184 unifocal hepatocellular carcinomas: association with tumor growth and invasiveness. Cancer Res 1993, 53(19):4691-4694.

25. Hsu HC, Peng SY, Lai PL, Chu JS, Lee PH: Mutations of p53 gene in hepatocellular carcinoma ( $\mathrm{HCC}$ ) correlate with tumor progression and patient prognosis: a study of 138 patients with unifocal HCC. Int J Oncol 1994, 4:1341-1347.

26. Wilkinson RW, Odedra R, Heaton SP, Wedge SR, Keen NJ, Crafter C, Foster JR, Brady MC, Bigley A, Brown E, Byth KF, Barrass NC, Mundt KE, Foote KM, Heron NM, Jung FH, Mortlock AA, Boyle FT, Green S: AZD1152, a selective inhibitor of Aurora B kinase, inhibits human tumor xenograft growth by inducing apoptosis. Clin Cancer Res 2007, 13(12):3682-3688.

27. Hosmer DW, Lemeshow S: Applied logistic regression. New York (NY): John Wiley \& Sons, 22000

28. Hosmer DW, Lemeshow S: Applied survival analysis: regression modeling of time to event data. New York (NY): John Wiley \& Sons 1999.

29. Satinover DL, Leach CA, Stukenberg PT, Brautigan DL: Activation of AuroraA kinase by protein phosphatase inhibitor-2, a bifunctional signaling protein. Proc Natl Acad Sci USA 2004, 101(23):8625-8630.

30. Fu J, Bian M, Jiang $Q$, Zhang C: Roles of Aurora kinases in mitosis and tumorigenesis. Mol Cancer Res 2007, 5(1):1-10.

31. Hu RH, Lee PH, Yu SC, Dai HC, Sheu JC, Lai MY, Hsu HC, Chen DS: Surgical resection for recurrent hepatocellular carcinoma: prognosis and analysis of risk factors. Surgery 1996, 120(1):23-29.

32. Sorrentino R, Libertini S, Pallante PL, Troncone G, Palombini L, Bavetsias V, Spalletti-Cernia D, Laccetti P, Linardopoulos S, Chieffi P, Fusco A, Portella G: Aurora $B$ overexpression associates with the thyroid carcinoma undifferentiated phenotype and is required for thyroid carcinoma cell proliferation. J Clin Endocrinol Metab 2005, 90(2):928-935.

33. Lee EC, Frolov A, Li R, Ayala G, Greenberg NM: Targeting Aurora kinases for the treatment of prostate cancer. Cancer Res 2006, 66(10):4996-5002.

34. Tanaka S, Arii S, Yasen M, Mogushi K, Su NT, Zhao C, Imoto I, Eishi Y, Inazawa J, Miki Y, Tanaka H: Aurora kinase B is a predictive factor for the aggressive recurrence of hepatocellular carcinoma after curative hepatectomy. Br J Surg 2008, 95(5):611-619.

35. Shen YC, Hu FC, Jeng YM, Chang YT, Lin ZZ, Chang MC, Hsu C, Cheng AL: Nuclear overexpression of mitotic regulatory proteins in biliary tract cancer: correlation with clinicopathologic features and patient survival. Cancer Epidemiol Biomarkers Prev 2009, 18(2):417-423.

36. Laurent-Puig P, Legoix P, Bluteau O, Belghiti J, Franco D, Binot F, Monges G, Thomas G, Bioulac-Sage P, Zucman-Rossi J: Genetic alterations associated with hepatocellular carcinomas define distinct pathways of hepatocarcinogenesis. Gastroenterology 2001, 120(7):1763-1773.

37. Zhou H, Kuang J, Zhong L, Kuo WL, Gray JW, Sahin A, Brinkley BR, Sen S: Tumour amplified kinase STK15/BTAK induces centrosome amplification, aneuploidy and transformation. Nat Genet 1998, 20(2):189-193.

38. Mountzios G, Terpos E, Dimopoulos MA: Aurora kinases as targets for cancer therapy. Cancer Treat Rev 2008, 34(2):175-182. 
39. Aihara A, Tanaka S, Yasen M, Matsumura S, Mitsunori Y, Murakata A, Noguchi N, Kudo A, Nakamura N, Ito K, Arii S: The selective Aurora B kinase inhibitor AZD1152 as a novel treatment for hepatocellular carcinoma. J Hepatol 2010, 52(1):63-71.

Pre-publication history

The pre-publication history for this paper can be accessed here: http://www.biomedcentral.com/1471-2407/10/461/prepub

doi:10.1186/1471-2407-10-461

Cite this article as: Lin et al:: Significance of Aurora $B$ overexpression in hepatocellular carcinoma. Aurora B Overexpression in HCC. BMC Cancer 2010 10:461.

Submit your next manuscript to BioMed Central and take full advantage of:

- Convenient online submission

- Thorough peer review

- No space constraints or color figure charges

- Immediate publication on acceptance

- Inclusion in PubMed, CAS, Scopus and Google Scholar

- Research which is freely available for redistribution

Submit your manuscript at www.biomedcentral.com/submit 